\title{
From the editor's desk...
}

I am pleased to place before you the Volume 8, Issue 1 of AJMR.

We at AIMIT are committed towards quality research and excellence in education. The last six months were very exceptional due to two reasons- International conference and recognition of research centre.

India is in the midst of economic, political and organizational transformation. While the nation as a whole and organizations in particular are striving towards excellence in all fields, the $B$ schools are striving towards providing learning environments to their scholars to equip them to apply pioneering methods in accomplishing the same. The International Conference on Innovative Practices in Business and Information Technology organized in December was one step towards it. The response was overwhelming with more than 200 authors from across the world contributing their research work in the areas of Finance, Marketing, Human Resources, Management and Information Technology. The conference was graced by the presence of Honourable Vice Chancellor of Bangalore University. The delegates from Stevenson University, USA contributed by sharing their research works in the areas of Information Technology. We also released two books with ISBN numbers-one with selected papers and the other as a compilation of abstracts.

The feather in the cap for this period was marked by AIMIT being recognized as a research centre of Bangalore University for Ph. D.

You have to have a big vision and take very small steps to get there. You have to be humble as you execute but visionary and gigantic in terms of your aspiration. It's not about grand innovation, it's about a lot of little innovations. every day, every week, every month, making something a little bit better.

Happy reading!!!

- Jason Calacanis

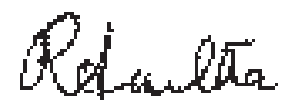

Dr. Anitha Ramachander

Chief Editor 